\title{
THE RELATION BETWEEN EXTERNAL POTASSIUM CONCENTRATION AND THE ELECTROLYTE CONTENT OF ISOLATED RAT MUSCLE IN THE STEADY STATE*
}

\author{
By ARNOLD S. RELMAN, GEORGE W. GORHAM † AND NORMAN G. LEVINSKY $\ddagger$ \\ WITH THE TECH NICAL ASSISTANCE OF ARLENE M. ROY AND \\ JACQUELYN M. ALLEN \\ (From the Evans Memorial Department of Clinical Research and Preicntive Medicine, Massa- \\ chusetts Memorial Hospitals, and the Department of Medicinc, Boston \\ University School of Medicine, Boston, Mass.)
}

(Submitted for publication August 3, 1960 ; accepted October 20, 1960)

There have been many studies of electrolyte fluxes in isolated mammalian muscle (1-4). However, there exists at present virtually no information about the factors which in vitro affect the steady state concentrations of intracellular electrolytes. To investigate this problem a technique for the incubation of intact rat diaphragms has been developed which permits the prolonged maintenance of muscle composition in a steady state.

The purpose of this communication is, first, to describe the technique and to present evidence that a stable and physiological tissue composition can be maintained for up to 12 hours. Second, data are presented which define the effects of varying external concentrations of potassium on muscle composition. Striking and unexpected differences between in vivo and in vitro behavior were encountered.

\section{METHODS}

Sprague-Dawley rats, 40 to $80 \mathrm{~g}$ in weight, were lightly anesthetized with intraperitoneal 4 per cent sodium amobarbital solution. The entire thoracic rib cage was dissected out, leaving the diaphragm intact. Special care was taken not to cut the diaphragm or its attachments. The diaphragm with the rib cage attached was then rinsed quickly in saline before being placed in the bathing medium.

The bathing solution was a modified Krebs-Ringer bicarbonate medium containing: $\mathrm{NaCl}, 115$ mmoles per $\mathrm{L}$; $\mathrm{NaHCO}_{3}, 25$ mmoles per L; $\mathrm{NaH}_{2} \mathrm{PO}_{4}, 1.2$ mmoles per $\mathrm{L}$; $\mathrm{MgSO}_{4}, 1.2$ mmoles per $\mathrm{L}$; and $\mathrm{CaCl}_{2}, 1.3$ mmoles

* Supported by the National Institutes of Health, Grant H2767. Presented in part before the American Physiological Society, April 1960.

† Postdoctoral Research Fellow, The National Foundation.

$\ddagger$ During tenure as a Special Research Fellow, United States Public Health Service. per $\mathrm{L} . \mathrm{KCl}$ was added as dictated by experimental design, the $\mathrm{Na}$ content remaining constant. Glucose, $100 \mathrm{mg}$ per $100 \mathrm{ml}$ was added in every case. For antibacterial effect, chloramphenicol, $62.5 \mathrm{mg}$ per L was used, sometimes supplemented with penicillin, $100,000 \mathrm{U}$ per L, and streptomycin, $100 \mathrm{mg}$ per $\mathrm{L}$.

The bathing solution was contained in a specially designed plastic box with a capacity of approximately $3 \mathrm{~L}$. The box had a sintered glass bottom plate which permitted vigorous aeration of the medium with 95 per cent $\mathrm{O}_{2}$, and 5 per cent $\mathrm{CO}_{2}$. The incubating box was kept in a constant temperature water bath which maintained the fluid in the box at $37^{\circ} \mathrm{C}$. The $\mathrm{pH}$ of the bathing solution, checked at intervals, was kept within the range of 7.37 and 7.43 .

At the beginning of an experiment 12 diaphragm preparations were placed in $1,500 \mathrm{ml}$ of bathing medium within the plastic box and secured to glass rods in order to keep them fully immersed. During the first hour of an experiment approximately $500 \mathrm{ml}$ of bathing solution was changed every 15 minutes. Thereafter $500 \mathrm{ml}$ was changed every 30 minutes until the end of the experiment.

At the end of an experiment the intact diaphragm preparations were washed in 5 per cent glucose solution and the two lateral muscular hemidiaphragms were rapidly dissected from their rib cage attachments and central tendons. The hemidiaphragms were then blotted once on filter paper, placed in tared test tubes and weighed. In rats of the size used in these experiments the muscular portion of the diaphragm is less than $0.5 \mathrm{~mm}$ in thickness (4 to 8 muscle fibers) and its total weight is $100 \mathrm{mg}$ or less. Thereafter the diaphragms were dried under vacuum at room temperature for 15 hours and reweighed to obtain dry weights. Muscle electrolytes were extracted in boiling water for 1 hour, a technique previously validated by comparisons with standard dry-ashing methods. Sodium and potassium analyses of the extract were made with a flame photometer and chloride analyses amperometrically with an Aminco-Cotlove chloride titrator. Diaphragms from in aiz'o control rats were extracted and analyzed in a similar fashion.

Inulin space was used as a measure of the extracellular space of tissue. At least 60 minutes before the diaphragm preparations were to be removed for analysis, 
they were transferred to a second bathing solution, identical with the first except for the presence of inulin, approximately 700 to $900 \mathrm{mg}$ per $100 \mathrm{ml}$. In agreement with the observations of Creese (5), it had previously been established that a period of 60 minutes was more than sufficient time to permit equilibration of the inulin.

The alkali-stable fraction of inulin in the tissue extracts was prepared for analysis by a modification ${ }^{1}$ of Cotlove's technique (6). Five $\mathrm{ml}$ of extract was placed in $10-\mathrm{ml}$ volumetric flasks, $1.6 \mathrm{ml}$ of $0.75 \mathrm{~N} \mathrm{NaOH}$ added, and the solutions heated in a water bath for 30 minutes. The $\mathrm{pH}$ was then adjusted with $1.5 \mathrm{~N} \mathrm{HCl}$ to approximately 7.0, using phenolphthalein as an indicator. Protein was precipitated by adding exactly $1 \mathrm{ml}$ of 10 per cent $\mathrm{ZnSO}_{4}$ and $1 \mathrm{ml}$ of $0.75 \mathrm{~N} \mathrm{NaOH}$. The solutions were then made up to $10 \mathrm{ml}$ volume, shaken, allowed to stand for 10 minutes, and centrifuged. Inulin analyses were performed on $2 \mathrm{ml}$ of the supernatant, using the resorcinol method of Roe, Epstein and Goldstein (7). The inulin analysis of the bathing solution was carried out in a similar fashion after appropriate dilution. To determine the in rivo inulin space of the diaphragms, bilateral nephrectomies were performed and $1.5 \mathrm{ml}$ of a 10 per cent inulin solution was injected intraperitoneally or intravenously. The animals were exsanguinated after 3 hours and the diaphragms analyzed for inulin as a1ready described. In in vivo and in vitro experiments an average blank correction for inulin was made by appropriate analyses of groups of diaphragms. Blank values were always less than 5 per cent of the total inulin color.

\section{RESULTS}

Stability of the preparation. Table I summarizes the results obtained in one series of experi-

1 The authors are grateful to Dr. Cotlove for suggesting this adaptation of his technique. ments in which diaphragms were incubated for periods up to 12 hours at a bath potassium concentration of $6 \mathrm{mE} q$ per L. Total water content, as per cent of wet weight, rose slightly during the course of the experiment. This was mainly due to a small increase in extracellular water, which became apparent at the ninth and twelfth hours. Intracellular water was relatively constant after a slight initial increase. At first, calculated intracellular potassium dropped by $18 \mathrm{mEq}$ per $\mathrm{L}$ from in vivo control levels and intracellular sodium rose by $29 \mathrm{mEq}$ per L. After these initial changes, intracellular electrolyte composition remained essentially constant throughout the 12 hour period. The sodium entering cell water in excess of the loss of potassium was accompanied by a simultaneous gain of intracellular chloride. The inherent inaccuracy of the calculation of intracellular sodium and chloride prevents any precise comparison between gains in these ions and the loss of potassium.

The stability and physiologic viability of the preparation is emphasized by the results of a group of experiments shown graphically in Figure 1. In these studies the muscles were placed in a potassium-free bath during the initial period of incubation. After 4 hours some of the muscles were taken for analysis and it was found that approximately half the potassium content had been lost in exchange for an equivalent amount of sodium. The rest of the diaphragms were then placed in

TABLE I

Changes in water compartments and electrolyte composition of rat diaphragm during incubation at bath potassium of $6 \mathrm{mEq}$ per $L$

\begin{tabular}{|c|c|c|c|c|c|c|c|c|c|}
\hline & \multirow[b]{2}{*}{ Water } & \multirow{2}{*}{$\begin{array}{l}\text { Inulin } \\
\text { space }\end{array}$} & \multicolumn{3}{|c|}{ Total content } & \multirow{2}{*}{$\begin{array}{l}\text { Intracellular } \\
\text { water }\end{array}$} & \multicolumn{3}{|c|}{ Intracellular conc. } \\
\hline & & & $\mathrm{K}$ & $\mathrm{Na}$ & $\mathrm{Cl}$ & & $\mathbf{K}$ & $\mathrm{Na}$ & $\mathrm{Cl}$ \\
\hline & \multicolumn{2}{|c|}{$\%$ wet wt } & \multicolumn{3}{|c|}{$m E q / 100 \mathrm{~g} d r y w t$} & $\mathrm{ml} / 100 \mathrm{~g} d r y w t$ & \multicolumn{3}{|c|}{$m E q / L I C W$} \\
\hline $\begin{array}{l}\text { In vivo } \\
\text { control }\end{array}$ & $\begin{array}{c}76 \pm 2 * \\
{[39] \dagger}\end{array}$ & $\begin{array}{c}17 \pm 2 \\
{[21]}\end{array}$ & $\begin{array}{c}40 \pm 2 \\
{[40]}\end{array}$ & $\begin{array}{c}12 \pm 2 \\
{[38]}\end{array}$ & $\begin{array}{l}4 \pm 1 \\
{[10]}\end{array}$ & $\begin{array}{c}251 \pm 20 \\
{[21]}\end{array}$ & $\begin{array}{c}158 \pm 8 \\
{[21]}\end{array}$ & $\begin{array}{l}8 \pm 6 \\
{[19]}\end{array}$ & $\stackrel{0}{0}$ \\
\hline $\begin{array}{l}\text { In vitro } \\
3 \text { hours }\end{array}$ & $\begin{array}{c}77 \pm 1 \\
{[30]}\end{array}$ & $\begin{array}{c}18 \pm 4 \\
{[23]}\end{array}$ & $\begin{array}{c}36 \pm 2 \\
{[29]}\end{array}$ & $\begin{array}{c}20 \pm 4 \\
{[27]}\end{array}$ & & $\begin{array}{c}261 \pm 21 \\
{[23]}\end{array}$ & $\underset{[22]}{140 \pm}$ & $\begin{array}{c}37 \pm 23 \\
{[20]}\end{array}$ & \\
\hline 6 hours & $\begin{array}{c}77 \pm 1 \\
{[36]}\end{array}$ & $\begin{array}{c}18 \pm 4 \\
{[29]}\end{array}$ & $\begin{array}{c}37 \pm 3 \\
{[36]}\end{array}$ & $\underset{[35]}{21 \pm 4}$ & & $\begin{array}{c}266 \pm 19 \\
{[29]}\end{array}$ & $\begin{array}{c}139 \pm 10 \\
{[29]}\end{array}$ & $\begin{array}{c}40 \pm 17 \\
{[28]}\end{array}$ & \\
\hline 9 hours & $\begin{array}{c}78 \pm 1 \\
{[30]}\end{array}$ & $\begin{array}{c}21 \pm 4 \\
{[25]}\end{array}$ & $\begin{array}{c}38 \pm 3 \\
{[28]}\end{array}$ & $\begin{array}{c}23 \pm 6 \\
{[27]}\end{array}$ & $\begin{array}{c}14 \pm 2 \\
{[10]}\end{array}$ & $\begin{array}{c}264 \pm 19 \\
{[25]}\end{array}$ & $\begin{array}{c}146 \pm 14 \\
{[24]}\end{array}$ & $\begin{array}{c}41 \pm 21 \\
{[23]}\end{array}$ & $\underset{[10]}{11 \pm 7}$ \\
\hline 12 hours & $\begin{array}{c}79 \pm 1 \\
{[22]}\end{array}$ & $\begin{array}{c}22 \pm 2 \\
{[19]}\end{array}$ & $\begin{array}{c}37 \pm 2 \\
{[22]}\end{array}$ & $\begin{array}{c}21 \pm 3 \\
{[22]}\end{array}$ & $\begin{array}{c}15 \pm 3 \\
{[6]}\end{array}$ & $\begin{array}{c}268 \pm 15 \\
{[19]}\end{array}$ & $\begin{array}{c}137 \pm 11 \\
{[19]}\end{array}$ & $\begin{array}{c}26 \pm 9 \\
{[19]}\end{array}$ & $\frac{8 \pm 6}{[6]}$ \\
\hline
\end{tabular}

* Mean \pm standard deviation.

$\dagger$ Number of analyses in brackets. 


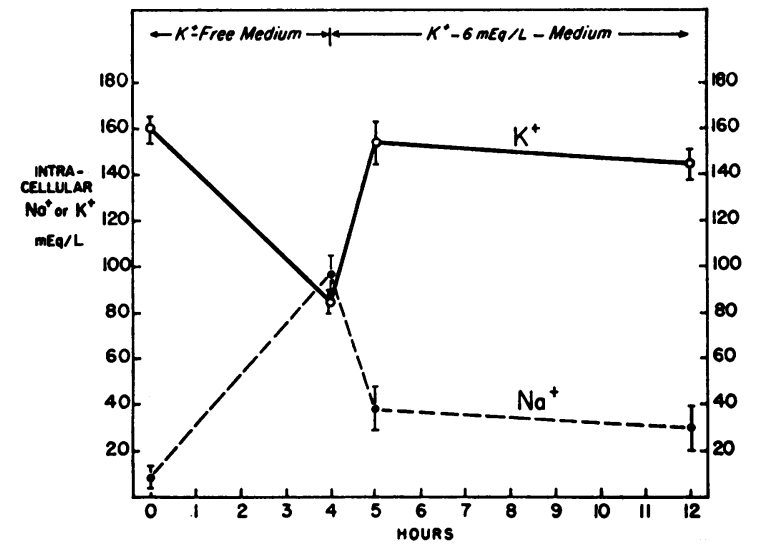

Fig. 1. Changes in intracellular potassium and SODIUM DURING LEACHING IN A POTASSIUM-FREE BATH AND FOLLOWING THE RESTITUTION OF POTASSIUM TO THE MEDIUM. Each point is the average of 15 to 25 muscle analyses. The vertical lines through each point represent the range of $\pm 2 \mathrm{SE}$.

a bath containing $6 \mathrm{mEq}$ per $\mathrm{L}$ of potassium. In this medium, the muscles rapidly reaccumulated potassium and extruded sodium, as evidenced by the "normal" in vitro potassium and sodium content after only 1 hour of incubation. Moreover, these concentrations were maintained in dia- phragms inculated for a full 8 hours after leaching, i.e., for a total inculation time of 12 hours.

Relation betwecn bath potassium and muscle potassium content. The time course of muscle potassium content at a variety of bath potassium concentrations is plotted in Figure 2. At a bath potassium of $6 \mathrm{mEq}$ per L muscle potassium was approximately constant throughout the final 9 hours of incubation, as noted above. At a bath potassium of $1.1 \mathrm{mEq}$ per $\mathrm{L}$, muscle potassium fell initially but then rose gradually until it reached the "normal" in vitro value for a bath potassium of 6 $\mathrm{mEq}$ per L. Potassium content then remained constant during the final 3 hours of incubation. At bath potassiums of less than $1 \mathrm{mEq}$ per L, muscle potassium content in each case fell progressively during the early hours of incubation, but then reached a relatively stable value during the final 4 hours in the bathing medium. The values for this final period, taken to represent an approximately steady state for potassium content, are shown in Figure 2 by the solid points in each line. Each point represents the average of 6 to 12 diaphragms. The mean of all the analyses indicated by the solid points in each line ( \pm its standard

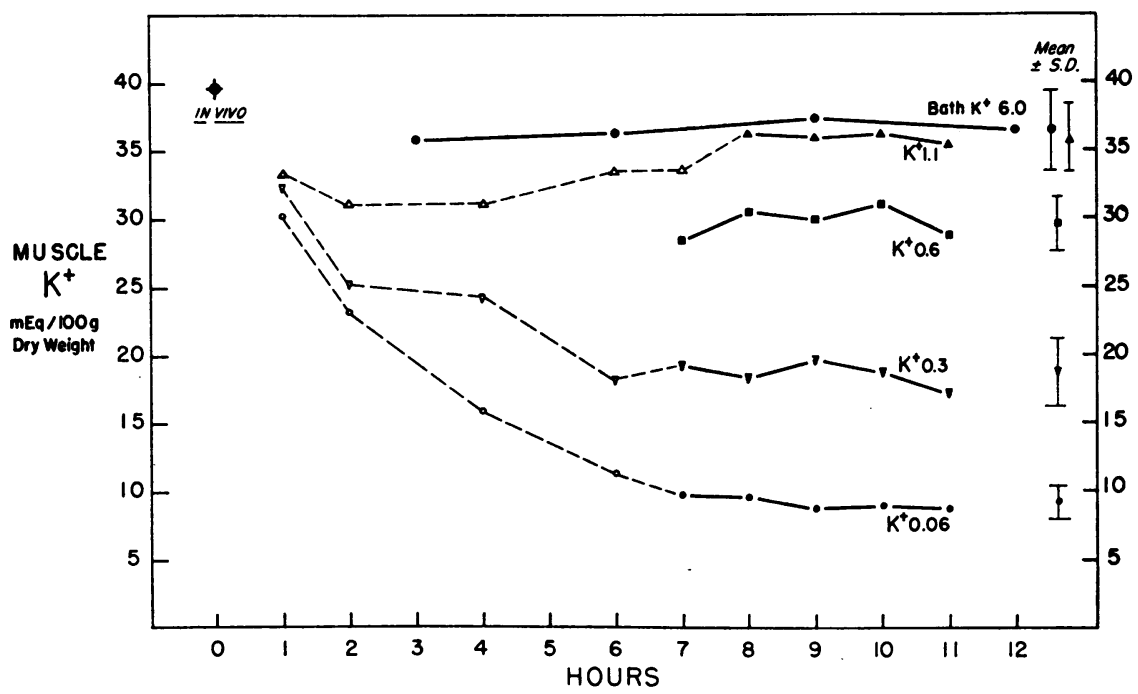

Fig. 2. Muscle potassium content during incubation at various external POTASSIUM CONCENTRATIONS. Each open point connected by broken lines represents the mean of relatively few diaphragms taken early in the experiments to show the general trend of muscle potassium. Each solid point connected by unbroken lines represents the mean of 6 to 12 diaphragms. The mean of all the solid points at each external potassium is represented by the point at the end of the appropriate curve, and the standard deviation of this mean is depicted by the vertical lines through each of these points. 
deviation) is plotted at the right of the appropriate curve. These mean potassium contents are each derived from no less than 24 diaphragms taken in at least two separate experiments, in which there was little or no change during the final 4 to 5 hours of incubation. Each mean is considered to approximate a steady state value for muscle potassium content at a given external potassium concentration.

The steady state muscle potassium contents from the experiments depicted in Figure 2, plus comparable values from similar experiments at other bath potassium concentrations, are plotted against external potassium concentration in Figure 3. Three facts about this relationship are worth particular comment. First, there was little or no change in muscle potassium as bath potassium was lowered from 6 to $1 \mathrm{mEq}$ per L. and at most a small increment in muscle potassium as bath potassium was raised to $9.5 \mathrm{mEq}$ per $\mathrm{L}$. At approximately $1 \mathrm{mEq}$ per $\mathrm{L}$ there was a sharp break in the curve and, at bath potassiums of less than 1 $\mathrm{mEq}$ per L, muscle potassium and bath potassium were linearly related. Because of continuing potassium loss from rib cage structures other than the diaphragm, it was not possible to achieve bath potassium concentrations of less than $0.06 \mathrm{mEq}$ per L. At this concentration (lowest point on curve in Figure 3), some $9 \mathrm{mEq}$ of potassium per $100 \mathrm{~g}$ dry weight remained in the diaphragm. Extra-

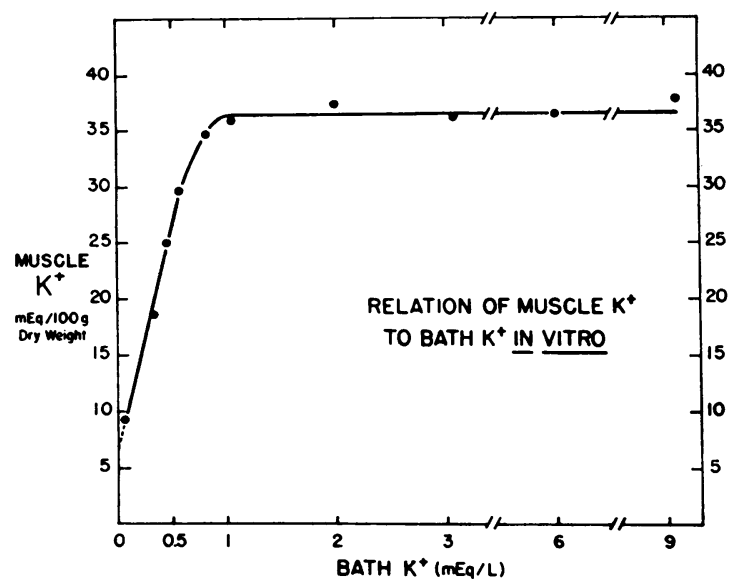

Fig. 3. Steady state diaphragm potassium content IN VITRO AS A FUNCTION OF EXTERNAL POTASSIUM CONCEntration. Each point represents the mean of 24 to 48 muscles from at least two separate experiments, showing little or no change in muscle potassium content for 3 to 5 hours. polation of the linear relationship of internal to external potassium from this point to zero external potassium (indicated by the dashed portion of the curve) suggests that some 6 to $7 \mathrm{mEq}$ of potassium per $100 \mathrm{~g}$ dry weight would remain in the muscles in a potassium-free bath.

Relation between bath potassium and muscle composition. The upper half of Table II shows the intracellular electrolyte composition of muscles at several external potassium concentrations of $1.1 \mathrm{mEq}$ per $\mathrm{L}$ or above. The values given at each bath potassium represent the means of 15 to 22 diaphragms taken after 8 to 10 hours of incubation in several separate experiments. As would be expected from the lack of change in potassium content per dry weight shown in Figure 3, intracellular potassium decreased relatively little as external potassium was lowered from 9.5 to 1.1 $\mathrm{mEq}$ per L. Intracellular sodium rose slightly, but chloride was virtually constant. Inulin space and extracellular water were also relatively stable. These results confirm the impression derived from Figure 3 that intracellular electrolyte composition was relatively constant over a wide range of external potassium concentrations greater than 1.1 $\mathrm{mEq}$ per L. ${ }^{2}$

Similar clata from three experiments at external potassium concentrations of less than $1 \mathrm{mEq}$ per $\mathrm{L}$ are summarized in the bottom half of Table II. In each experiment the fall in intracellular potassium concentration from that found at a bath potassium of $1.1 \mathrm{mEq}$ per $\mathrm{L}$ was balanced by an approximately equal rise in intracellular sodium. There was little or no change in intracellular chloride. There was no eviclence of a significant cation deficit in cells during in vitro potassium depletion of muscles, and thus no need to postulate a shift of hydrogen ion or other cations to account for these data.

Differences between the effect of lowered external potassium in vivo and in vitro. Other in-

2 Note that the values for inulin space and intracellular water and electrolytes were somewhat different at an external potassium of $5.5 \mathrm{mEq}$ per $\mathrm{L}$, in this group of experiments, from those shown in Table $I$. The two groups of experiments were separated by a year or more. We have no explanation for these differences, in terms of changes in technique, animal size or strain, and so forth; however, results have been quite consistent during the course of the year or more during which the studies shown in Table II were carried out. 
TABLE II

Effects of bath potassium on water compartments and electrolyte composition of rat diaphragm

\begin{tabular}{|c|c|c|c|c|c|c|}
\hline \multirow{2}{*}{$\underset{\mathrm{K}}{\text { Bath }}$} & \multirow{2}{*}{$\begin{array}{l}\text { Inulin } \\
\text { space }\end{array}$} & \multirow{2}{*}{$\begin{array}{l}\text { Intracellular } \\
\text { water }\end{array}$} & \multicolumn{4}{|c|}{ Intracellular electrolytes } \\
\hline & & & $\mathrm{K}$ & $\mathrm{Na}$ & $\mathrm{Na}+\mathrm{K}$ & $\mathrm{Cl}$ \\
\hline$m E q / L$ & $\%$ wet wt & $m l / 100 \mathrm{~g} d r y w t$ & \multicolumn{4}{|c|}{$m E q / L$ intracellular water } \\
\hline $\begin{array}{l}9.5 \\
{[15] \dagger}\end{array}$ & $26 \pm 3^{*}$ & $230 \pm 15$ & $167 \pm 8$ & $11 \pm 5$ & $178 \pm 8$ & $4 \pm 4$ \\
\hline $\begin{array}{c}5.5 \\
{[18]}\end{array}$ & $25 \pm 2$ & $229 \pm 11$ & $162 \pm 6$ & $15 \pm 5$ & $177 \pm 7$ & $4 \pm 3$ \\
\hline $\begin{array}{l}1.1 \\
{[22]}\end{array}$ & $24 \pm 3$ & $239 \pm 10$ & $148 \pm 8$ & $23 \pm 7$ & $172 \pm 7$ & $6 \pm 3$ \\
\hline $\begin{array}{r}0.45 \\
{[6]}\end{array}$ & $26 \pm 1$ & $243 \pm 9$ & $116 \pm 6$ & $48 \pm 7$ & $164 \pm 8$ & $4 \pm 4$ \\
\hline $\begin{array}{r}0.29 \\
{[5]}\end{array}$ & $25 \pm 2$ & $227 \pm 6$ & $84 \pm 4$ & $93 \pm 6$ & $177 \pm 4$ & $13 \pm 8$ \\
\hline $\begin{array}{r}0.25 \\
{[6]}\end{array}$ & $27 \pm 1$ & $222 \pm 13$ & $68 \pm 7$ & $106 \pm 7$ & $174 \pm 8$ & $10 \pm 5$ \\
\hline
\end{tabular}

$*$ Mean \pm SD.

$\dagger$ Number of diaphragms in brackets.

vestigators (8) have reported that there is an approximately linear relationship between peripheral skeletal muscle potassium and plasma potassium during potassium depletion in vivo. The data presented above indicate that muscle potassium changes but little when external potassium is decreased over the range found in plasma during potassium depletion in vivo. To confirm this apparent difference between the in vivo and in vitro results, two sets of experiments were done. In the first type of experiment, groups of rats similar in size to those used for the in vitro experiments were placed on a potassium-free diet for one to three weeks. ${ }^{3}$ At intervals, small groups were killed and plasma and diaphragms were analyzed for potassium. The results are shown by the points in Figure 4, each of which represents a single animal. The observed relationship between diaphragm potassium and plasma potassium can be described by a straight line- $y=4 x+23.5$ (the heavy line in Figure 4); the correlation coefficient $(R)$ is 0.7 : These in vivo results, showing a linear relationship between diaphragm and plasma potassium, confirm the data of Welt and co-workers (8) obtained with other skeletal mus-

${ }^{3}$ The diet used was low in alkali, and bicarbonate was not added to the drinking water. Although potassiumdeficient, these animals did not become alkalotic, as evidenced by plasma $\mathrm{CO}_{2}$ values in the same range as those of control rats ( 25 to 30 mmoles per $\mathrm{L}$ ). cles. They contrast sharply with the in vitro relationship described by the dotted line in Figure 4.

This difference between the in vitro and in vivo relation of internal to external potassium was demonstrated in another way by the results of a second type of experiment which are summarized in Table III. Thirty-nine rats were placed on a potassium-free diet for several weeks,

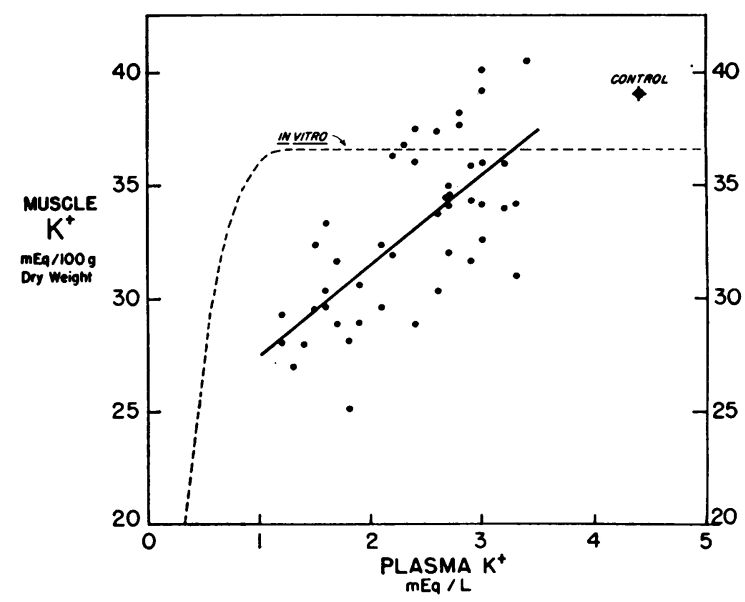

Fig. 4. Relation of DiAPHRAGM POTASSIUM to Plasma POTASSIUM IN VIVO. Each point represents the values from one potassium-depleted rat. The solid line has been fitted to these points by the method of least mean squares. The dashed line is the in vitro curve from Figure 3 . The point labeled "control" is the mean in vivo diaphragm potassium from 51 normal rats. 
T.IBLLE HII

Effect of incubation on potassium content of diaphragms from potassium-depleted rats

\begin{tabular}{lccc}
\hline \hline & Plasma $\mathrm{K}$ & Bath $\mathrm{K}$ & Muscle $\mathrm{K}$ \\
\hline & $m E q / L$ & $m E q / L$ & $\begin{array}{c}m E q / 100 \mathrm{~g} \\
\text { drywt }\end{array}$ \\
In vivo [16] & $1.6 \pm 0.3$ & & $29.5 \pm 2.1$ \\
In vitro [23] & $1.7 \pm 0.3$ & 1.1 & $34.3 \pm 3.1$ \\
\hline
\end{tabular}

after which 16 of these animals selected at random were killed and their diaphragms taken for analysis. Diaphragms from the remaining 23 rats were incubated for 8 to 10 hours in a bath containing 1.1 mEq per $\mathrm{L}$ potassium. The mean plasma potassium concentrations of the two groups were equal. and considerably higher than the bath potassium concentration. Nevertheless, the incubated diaphragms actually gained potassium to approximately the "normal" in vitro level. Thus muscle potassium content increased significantly $(\mathrm{p}<$ 0.001 ) when the diaphragms were taken from a higher external potassium in z'iz'o to a lower external potassium in ritro.

\section{DISCUSSION}

An in vitro muscle preparation suitable for the study of steady state phenomena should be capable of maintaining its cellular water content and electrolyte concentrations close to in viz'o levels when incubated in simple physiological media. Cell composition, furthermore, should remain reasonably steady over relatively prolonged periods of time. Rat diaphragm muscle has been widely used for various types of physiological and biochemical studies because it is easily handled and particularly because its thin shape facilitates the rapid equilibration of oxygen and other solutes between muscle and medium. However, cut diaphragm preparations when incubated usually show a progressive loss of potassium and a gain of sodium and water $(9,10)$. Creese (5) described a cut preparation which appeared capable of maintaining a nearly normal intracellular potassium content for as long as 12 hours, but its intracellular sodium content increased markedly.

Kipnis and Cori (11) pointed out several years ago that an "intact" cliaphragm preparation in which the fibers are left attached to ribs and central tendon offers important advantages for the study of normal cellular permealsility to sugars. It seemed reasonable to expect that electrolyte equilibrium in such an intact diaphragm would also be more satisfactory, and such has proven to be the case in the present experiments. The technique described here not only permits the maintenance of a nearly physiological cellular sodium. potassium and water content for many hours, but also possesses the additional advantages of simplicity and convenience. Moreover, many diaphragms may be handled simultaneously with relative ease.

The most striking observation made in these experiments was the relative constancy of tissue potassium as external potassium was varied from normal extracellular levels down to very low levels. As shown in Table II, the intracellular concentration of potassium decreased by only 10 per cent when bath potassium was reduced from 5.5 to $1.1 \mathrm{mEq}$ per $\mathrm{L}$, and the total potassium content of the tissue decreased by less than 5 per cent (Figure 3). This contrasts sharply with the steep slope of the line relating external potassium to skeletal muscle potassium content in potassiumdepleted animals found by Welt and co-workers in peripheral muscle $(8)$ and confirmed here for diaphragm muscle (Figure 4). In i'iz'o, muscle loses 30 per cent or more of its potassium content when plasma potassium is reduced from 4 to 1 mEq per I. When total exchangeable potassium is used as a rough index of tissue potassium content, similar large reductions in tissue potassium with even smaller reductions in plasma potassium can be inferred from observations in potassiumdepleted patients (12). Balance studies in two patients with severe chronic potassium depletion (13) indicated a loss of approximately 25 per cent of cellular potassium content with a reduction in plasma potassium to the range of 2.1 to 2.7 $\mathrm{mEq}$ per L.

Extracellular acidity is known to affect the in vivo relationship between extra- and intracellular potassium, and there may well be other important influences, as yet undefined. However, it is clear from the studies of Welt and co-workers that a reduction in extracellular potassium will lower muscle potassium content in rats with normal extracellular acid-base balance as much as in alkalotic animals. Futhermore, as already noted, the potassium-depleted rats used in the present 
in viz'o experiments dicl not become alkalotic. Therefore, the difference between the in aiz'o and in vitro behavior of muscle potassium is not to be attributed to the constancy of the $\mathrm{pH}$ and bicarbonate content of the incubation medium used in the present studies. The present data make it clear that loss of muscle potassium in potassium depletion is not solely the result of a lowered extracellular concentration of potassium. Other important factors must be involved. Current studies in this laboratory are concerned with this problem.

When the concentration of potassium in the medium was lowered below $1 \mathrm{mEq}$ per L, muscle potassium content began to decline and, as shown in Figure 3, at medium levels below $1 \mathrm{mEq}$ per $\mathrm{L}$ there was a direct linear correlation between internal and external potassium. While the data do not rule out a more complex mechanism, it is tempting to speculate that the simple and distinctive shape of the curve in Figure 3 reflects the operation of a single physical process responsible for potassium accumulation. However, the available information does not permit a critical choice among the various mechanisms proposed for this process. Thus, a relationship of this general type might be anticipated if potassium accumulation were entirely the passive consequence of the active extrusion of sodium (2). In that case, as external potassium is lowered, a critical concentration might be reached below which net influx of sodium and consequent loss of potassium might begin. Such an effect might depend on a relationship between external potassium and either sodium pumping or the passive permeability of the membrane to sodium. Alternatively, a curve similar to Figure 3 might also be anticipated if potassium accumulation were the result of active inward transport (14) either as a process independent of sodium efflux, or coupled with it (4). Under either of these latter possibilities, the distinctive shape of the curve could be determined by a saturation phenomenon. A similar explanation could also apply if potassium accumulation were the result of the specific attraction of potassium to fixed negative charges inside the cell (15-18).

Another feature of the data in Table II worth comment is the relationship between loss of intracellular potassium and gain of intracellular sodium. As shown in the column headed " $\mathrm{Na}+\mathrm{K}$ " the sum of these two ions remained approximately constant as bath potassium was lowered from 9.5 to $0.25 \mathrm{mE}$ q per $\mathrm{L}$, indicating roughly equivalent replacement of potassium by sodium. This is true even if a correction is made for the small and statistically insignificant rise in intracellular chloride at the lowest levels of bath potassium. In most studies of the effects of potassium-depletion on rat muscle in vivo, the rise in intracellular sodium is found to be only 70 or 80 per cent of the total loss of intracellular potassium (19-21). Although many workers have assumed that a shift of hydrogen ions into cells makes up this deficit, more recent studies by Eckel, Norris and Pope (21) have shown that in rats the apparently missing cation can sometimes be accounted for by the intracellular accumulation of cationic amino acids, chiefly lysine. No amino acids were added to the bathing medium in the present experiments, and therefore no cationic amino acids could have been available for exchange with intracellular potassium. The data in Table II demonstrate that, despite this, no significant hydrogen-for-potassium exchange occurred.

Finally, it should be noted that extrapolation of the curve in Figure 3 suggests the existence of a significant fraction of tissue potassium which is relatively nondiffusible. This fraction seems nevertheless to be able to exchange freely, since Creese found that $\mathrm{K}^{42}$ appeared to equilibrate with total tissue potassium in diaphragms incubated at $38^{\circ} \mathrm{C}$ (5). It is interesting, however, that at lower temperatures, an apparently nonexchangeable moiety can be demonstrated both in rat diaphragm (22, 23) and in extensor digitorum longus (24). Heterogeneity of intracellular potassium has been suggested by many workers and might conceivably result either from separation into subcellular compartments or from binding of potassium to intracellular constituents.

\section{SUM MARY AND CONCLUSIONS}

A method is described for the incubation of intact rat diaphrgams which permits the maintenance of a stable and physiological tissue composition for periods up to 12 hours. A study of the steady state relationship between internal composition and external potassium concentration revealed:

1. Below bath potassium concentrations of 1 $\mathrm{mEq}$ per $\mathrm{L}$ there was a linear relation between 
muscle potassium content and bath concentration. Intracellular potassium was replaced by virtually equivalent amounts of sodium.

2. At a bath potassium of 0.06 , about one-fourth of the total tissue potassium remained in situ and extrapolation to a potassium-free medium suggests the existence of a significant fraction of intracellular potassium which is relatively nondiffusible.

3. There was essentially no change in muscle potassium as bath potassium was lowered from 5.5 to $1.1 \mathrm{mEq}$ per L. By contrast, comparable changes in plasma potassium in intact potassiumdeficient rats were found to be accompanied by large reductions in diaphragm potassium.

It is concluded that reduction in external potassium concentration alone is insufficient to produce the loss of muscle potassium observed in potassium-deficient rats. The striking difference between the in riz'o and in zitro behavior of skeletal muscle cannot be explained by changes in extracellular acid-base balance; other as yet unidentified factors must play a role.

\section{ACKNOWLEDGMENT}

Dr. Harvey C. Gonick participated in the preliminary phases of these experiments.

\section{REFERENCES}

1. Harris, E. J. Transport and Accumulation in Biological Systems, 2nd ed. New York, Academic Press, 1960, chapter 7.

2. Conway, E. J. Nature and significance of concentration relations of potassium and sodium ions in skeletal muscle. Physiol. Rev. 1957, 37, 84.

3. Shanes, A. M. Electrochemical aspects of physiological and pharmacological action in excitable cells. Pharmacol. Rev. 1958, 10, 59.

4. Glynn, I. M. Sodium and potassium movements in nerve, muscle, and red cells. Int. Rev. Cytol. 1959, 8, 449.

5. Creese, R. Measurement of cation fluxes in rat diaphragm. Proc. Roy. Soc. B 1954, 142, 497.

6. Cotlove, E. Mechanism and extent of distribution of inulin and sucrose in chloride space of tissues. Amer. J. Physiol. 1954, 176, 396.

7. Roe, J. H., Epstein, J. H., and Goldstein, N. P. A photometric method for the determination of inulin in plasma and urine. J. biol. Chem. 1949, 178, 839.

8. Welt, L. G., Cap, M. P., Gehan, E. A., Winters, R. W., DeWalt, J. L., and Diamond, E. L. The pre- diction of muscle potassium from blood electrolytes in potassium depleted rats. Trans. Ass. Amer. Phycns 1958, 71, 250.

9. Calkins, E., Taylor, I. M., and Hastings, A. B. Potassium exchange in the isolated rat diaphragm; effect of anoxia and cold. Amer. J. Physiol. 1954, 177, 211.

10. Rixon, R. H., and Stevenson, J. A. F. Movements of sodium, potassium and water in rat diaphragm in vitro. Amer. J. Physiol. 1958, 194, 363.

11. Kipnis, D. M., and Cori, C. F. Studies of tissue permeability. III. The effect of insulin on pentose uptake by the diaphragm. J. biol. Chem. 1957, 224, 681.

12. Leibman, J., and Edelman, I. S. Interrelations of plasma potassium concentration, plasma sodium concentration, arterial $\mathrm{pH}$ and total exchangeable potassium. J. clin. Invest. 1959, 38, 2176.

13. Schwartz, W. B., and Relman, A. S. Metabolic and renal studies in chronic potassium depletion resulting from overuse of laxatives. J. clin. Invest. 1953, 32, 258.

14. Relman, A. S., Lambie, A. T., Burrows, B. A., and Roy, A. M. Cation accumulation by muscle tissue: The displacement of potassium by rubidium and cesium in the living animal. $\mathrm{J}$. clin. Invest. 1957, 36, 1249.

15. Ling, G. Muscle electrolytes. Amer. J. phys. Med. 1955, 34, 89.

16. Shaw, F. H., and Simon, S. E. The nature of the sodium and potassium balance in nerve and muscle cells. Aust. J. exp. Biol. med. Sci. 1955, 33, 153.

17. Simon, S. E. Ionic partition and fine structure in muscle. Nature (Lond.) 1959, 184, 1978.

18. Menozzi, P., Norman, D., Polleri, A., Lester, G., and Hechter, O. Specific intracellular binding of rubidium by rat diaphragm muscle. Proc. nat. Acad. Sci. (Wash.) 1959, 45, 80.

19. Cotlove, E., Holliday, M. A., Schwartz, R., and Wa1lace, W. M. Effects of electrolyte depletion and acid-base disturbance on muscle cations. Amer. J. Physiol. 1951, 167, 665.

20. Cooke, R. E., Segar, W. E., Cheek, D. B., Coville, F. E., and Darrow, D. C. The extrarenal correction of alkalosis associated with potassium deficiency. J. clin. Invest. 1952, 31, 798.

21. Eckel, R. E., Norris, J. E. C., and Pope, E. C. II. Basic amino acids as intracellular cations in $\mathrm{K}$ deficiency. Amer. J. Physiol. 1958, 193, 644.

22. McLennan, $H$. The transfer of potassium between mammalian muscle and the surrounding medium. Biochim. biophys. Acta 1955, 16, 87.

23. Hashish, S. E. E. The effects of low temperatures and heparin on potassium exchangeability in rat diaphragm. Acta physiol. scand. 1958, 43, 189.

24. McLennan, H. Physical and chemical factors affecting potassium movements in mammalian muscle. Biochim. biophys. Acta 1956, 22, 30. 